\title{
Interactions of follicular factors and season in the regulation of circulating concentrations of gonadotrophins in mares
}

\author{
F. X. Donadeu ${ }^{1}$ and O. J. Ginther ${ }^{1,2 *}$ \\ ${ }^{1}$ Department of Animal Health and Biomedical Sciences, University of Wisconsin, Madison, \\ WI 53706, USA; and ${ }^{2}$ Eutheria Foundation, Cross Plains, WI 53528, USA
}

Follicle growth and associated changes in circulating hormone concentrations were evaluated after follicle ablation in mares $(n=13)$ during four 13 day periods beginning at means of $-98.5,-61.4,-26.0$ and 10 days from the first ovulation and corresponding to midanovulatory, early-transitional, late-transitional and ovulatory periods, respectively. During each period, all follicles $>5 \mathrm{~mm}$ in diameter were ablated (day 0) followed by no subsequent ablations (all-follicle group) or the ablation of all follicles $>5 \mathrm{~mm}$ when a new follicle reached $>10 \mathrm{~mm}$ ( 0 -follicle group). A follicular wave emerged at means of days 1.5-2.5 in all mares of the all-follicle group during each period. Follicle activity increased between the midanovulatory and the transitional periods, as indicated by increases in the diameter of the largest follicle and the number of follicles in the all-follicle groups; nonetheless, there were no differences in the FSH concentrations of the wave-stimulating surge throughout the study. Circulating total inhibin increased between day 3 and day 6 in the all-follicle groups but not in the 0 -follicle groups, and was higher during the late-transitional and ovulatory periods than during earlier periods in the all-follicle groups. In the all-follicle groups, circulating FSH decreased between day 3 and day 6 . In the 0 -follicle groups, FSH did not decrease and was higher during the late-transitional and ovulatory periods than during the mid-anovulatory period. Circulating LH was higher during the late-transitional and ovulatory periods than during earlier periods and was not different between the all-follicle and 0 -follicle groups. On the basis of temporal relationships, it was concluded that the follicles of a wave secreted inhibin during all periods and the follicular inhibin suppressed circulating FSH. An increase in circulating inhibin induced by the growth of follicles $>21 \mathrm{~mm}$ in diameter during the late-transitional and ovulatory periods counteracted a stimulatory effect on FSH mediated by season.

\section{Introduction}

The annual reproductive cycle in mares is characterized by minimal follicular activity during short days (anovulatory season) and maximal activity during long days (ovulatory season; Turner et al., 1979). Donadeu and Ginther (2002a) determined two distinct periods of follicular activity during the second half of the anovulatory season: the mid-anovulatory and transitional periods. The diameter of the largest follicle averaged over all days during each period was 16.0 and $22.4 \mathrm{~mm}$, respectively. The two periods were separated by an increase over a mean of 7 days in the diameter and number of follicles beginning a mean of 52 days before ovulation. Follicular waves were demonstrated during both the mid-anovulatory and the transitional periods; the higher follicular activity during the transitional period resulted in waves being detected at a later stage of development than during the mid-anovulatory

*Correspondence

Email: ojg@ahabs.wisc.edu period. In addition, the early portion of the waves was not characterized because of the intermeshing of growing and regressing follicles from adjacent waves. Temporal relationships indicated that the follicular waves during the second half of the anovulatory season were stimulated by FSH surges. The characteristics of the FSH surges were similar between the middle and transitional periods of the anovulatory season, despite the higher follicular activity of the transitional period.

Circulating FSH concentrations are regulated by an interaction of season and the ovaries (reviewed in Ginther, 1992). During the middle of the anovulatory season, circulating FSH concentrations are inhibited by the short photoperiod. During the ovulatory season, FSH is stimulated by the long photoperiod and rhythmically inhibited by the ovaries. Seasonal effects on circulating $\mathrm{FSH}$ are mediated by changes in GnRH secretion, and ovarian negative effects on FSH are mediated by the follicular products, oestradiol and inhibin. Follicular production of oestradiol is reduced during the anovulatory season and an increase in production and secretion of oestradiol does not occur until the late transition 
(Davis and Sharp, 1991; Peltier et al., 1998; Donadeu and Ginther, 2002a; Watson and Al-zi'abi, 2002; Watson et al., 2002). Circulating concentrations of immunoreactive or total inhibin (Donadeu and Ginther, 2002a) and inhibin-A and free $\alpha$-subunit forms (Watson et al., 2002) are low during the middle of the anovulatory season and increase during the transitional period in association with an increase in follicular activity. Studies have led to similar conclusions regardless of whether the inhibin assay was based on total inhibin or inhibin-A. Temporal relationships in seasonally anovulatory mares indicate that circulating FSH is suppressed by inhibin from the growing follicles of a wave (Donadeu and Ginther, 2002a). The higher circulating inhibin concentrations associated with follicular waves during late transition than during early transition or the middle of the anovulatory season does not result in lower FSH concentrations during late-transitional waves. The absence of a circulating FSH response to the increased inhibin during late transition may reflect a seasonal effect on circulating FSH. However, the relative involvement of the effects of follicles versus season in the regulation of circulating FSH during the anovulatory season has not been studied.

Circulating LH concentrations are low throughout the second half of the anovulatory season and increase only during several days before the first ovulation (reviewed in Ginther, 1992). A slight increase in mean circulating LH concentrations (Donadeu and Ginther, 2002a) and an increase in circulating LH pulse frequency (Fitzgerald et al., 1987; Alexander and Irvine, 1991) occur throughout the second half of the anovulatory season. It is not known whether slight changes in LH during follicular waves account for the greater follicle growth during the transitional period in the absence of changes in the characteristics of FSH surges. Circulating LH concentrations are similar in ovariectomized and ovaryintact mares during the anovulatory season (Freedman et al., 1979). Sharp et al. (1991, 2001) concluded that the large follicles at the end of the anovulatory season are involved in the increase in circulating $\mathrm{LH}$ before the first ovulation of the year, through an increase in the production of oestradiol. The role of follicles in the regulation of circulating $\mathrm{LH}$ concentrations during the anovulatory season needs clarification.

The objectives of the present study were to compare follicular waves and associated changes in circulating concentrations of oestradiol, total inhibin, FSH and LH among different periods of the second half of the anovulatory season and early-ovulatory season, and to differentiate follicular from seasonal effects on circulating $\mathrm{FSH}$ and $\mathrm{LH}$ concentrations during each period. Follicle ablation was used to provide a uniform follicle population at the beginning of each period. In addition, two groups in which all follicles or no follicles were ablated were included to distinguish follicular from non-follicular effects during each period.
The hypotheses were that (1) the wave-associated FSH decline is similar between the mid-anovulatory and transitional periods, despite higher circulating inhibin concentrations associated with transitional waves; (2) the absence of an increased reduction in $\mathrm{FSH}$ in response to the increased circulating inhibin during transition is attributable to a positive counteracting seasonal effect on $\mathrm{FSH}$; and (3) an increase in follicle activity at the beginning of transition is temporally associated with an increase in circulating $\mathrm{LH}$.

\section{Materials and Methods}

\section{Animals and follicles}

Thirteen non-lactating pony mares of mixed breeding, aged 9-16 years, body weight $230-400 \mathrm{~kg}$, were kept under natural light in an open shelter and outdoor paddock in the Northern Hemisphere $\left(43^{\circ} \mathrm{N}\right.$; Wisconsin). Mares were fed alfalfa/grass hay and had free access to water and mineralized salt. Approval from the Animal Care Committee of the University of Wisconsin was obtained for the animal protocols.

All mares in which a corpus luteum was detected during the first 30 days of the experiment were removed to ensure that mares were anovulatory at the beginning of the study. The experiment involved successive 13 day periods, beginning every 35 days from 29 January until the first ovulation of the year and an additional 13 day period beginning 10 days after the first ovulation of the year. A duration of 13 days was chosen because it encompasses the development of an ablation-induced follicular wave during an oestrous cycle (Gastal et al., 1997; Donadeu and Ginther, 2001). At the beginning of each 13 day period (day 0 ), each mare was randomly assigned to all-follicle or 0 -follicle groups. In both groups, all follicles $>5 \mathrm{~mm}$ in diameter were ablated on day 0 to eliminate follicles from previous waves and provide a uniform follicle status at the beginning of each period. In the 0 -follicle group, new follicles $>5 \mathrm{~mm}$ in diameter were ablated during the daily examinations between days 1 and 10 whenever a follicle $>10 \mathrm{~mm}$ was detected. A diameter of $>10 \mathrm{~mm}$ was used for ablation of new follicles in the 0-follicle group because the follicles of a wave acquire the capacity to suppress FSH when the largest follicle reaches about $13 \mathrm{~mm}$ in diameter (Gastal et al., 1997; Bergfelt et al., 2001; Donadeu and Ginther, 2001). Follicle ablation was carried out by ultrasound-guided transvaginal aspiration of follicular contents (Gastal et al., 1997). Follicles that refilled with fluid to $>10 \mathrm{~mm}$ in diameter were re-ablated.

During each 13 day period, ovaries were monitored daily with an ultrasound scanner equipped with a $5 \mathrm{MHz}$ linear-array transducer (Aloka SSD-500V; Aloka, Wallingford, CT). At each scanning session, the diameter of $5-10 \mathrm{~mm}$ follicles was estimated by comparison with the graduation marks on the scanner screen 
and follicles $>10 \mathrm{~mm}$ were measured with electronic calipers (Ginther, 1995). Follicles were measured in two planes and the average of length and width from a frozen image was used as the diameter. Initially, during each experimental period, all follicles were tracked from day to day to identify the follicles of the post-ablation wave. Subsequently, beginning when a follicle $>10 \mathrm{~mm}$ in diameter was first identified, only follicles $>10 \mathrm{~mm}$ were tracked. Mares were scanned every 3 or 4 days between the experimental 13 day periods, and the presence of a corpus luteum was used to indicate that ovulation had occurred.

Individual mares had four (two mares), three (10 mares) or two (13 mares) experimental periods from the beginning of the experiment to the first ovulation. Data for the last three experimental periods before ovulation were used for statistical analyses. On the basis of results from the previous study during the second half of the anovulatory season (Donadeu and Ginther, 2002a), the three periods were designated as mid-anovulatory period, early-transitional period, and late-transitional period. The experimental period after the first ovulation was designated as the ovulatory period. A schematic representation of the experimental protocol is shown (Fig. 1).

Follicular waves were identified by a variation of a method described by Ginther and Kot (1994). A follicular wave was defined as two or more new follicles reaching $13 \mathrm{~mm}$ in diameter on consecutive days or every other day. Follicles reaching a diameter of $13 \mathrm{~mm}$ on two or more days after the previous follicle reached $13 \mathrm{~mm}$ were considered as belonging to a different wave. One or two follicular waves were detected per period in each mare. However, because of the limited duration of the periods, only the initial portion of the second wave was identified in most mares. Therefore, only data for the first follicular wave were used for statistical analyses. Emergence of the first post-ablation follicular wave was considered to occur on the day a follicle of the wave first reached $6 \mathrm{~mm}$ in diameter. For analyses involving measurements over time, the endpoints for the largest follicle refer to the largest follicle for each day without consideration of dayto-day identity.

\section{Blood sampling and hormone assays}

A jugular blood sample was collected into heparinized tubes daily during each experimental period for assay of circulating hormone concentrations. Blood samples were immediately centrifuged at $1500 \mathrm{~g}$ for $6 \mathrm{~min}$ and the plasma fraction was separated and stored at $-20^{\circ} \mathrm{C}$. Circulating concentrations of FSH and LH were measured by double antibody radioimmunoassay (Donadeu and Ginther, 2002b). Intra-assay CV, interassay CV and assay sensitivity were $12.4 \%, 13.4 \%$ and $1.4 \mathrm{ng} \mathrm{FSH} \mathrm{ml}^{-1}$, respectively; and $7.8 \%, 5.5 \%$ and $0.1 \mathrm{ng} \mathrm{LH} \mathrm{ml}^{-1}$, respectively. Sensitivity for all hormones was calculated

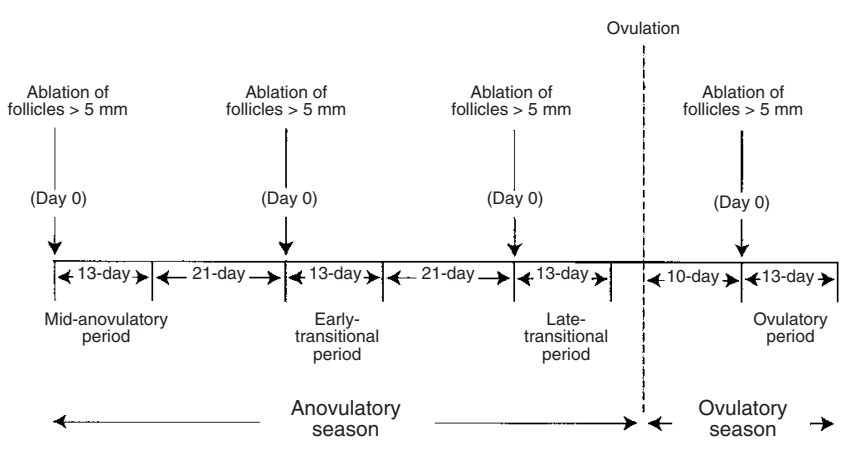

Fig. 1. Schematic representation of the experimental design in the all-follicle groups of mares. In the 0-follicle groups (not shown), the design was the same except that follicles $>5 \mathrm{~mm}$ in diameter were ablated when a new follicle reached $>10 \mathrm{~mm}$ between day 1 and day 10 .

by subtracting two standard deviations from the mean maximum percentage binding and averaging over all assays.

Plasma concentrations of total inhibin were measured by a double antibody radioimmunoassay kit (Institute of Reproduction and Development, Monash Medical Center, Clayton, Victoria; Donadeu and Ginther, 2001). The assay measures both dimeric inhibin and free $\alpha$-subunit forms (Roser et al., 1994). Intra-assay and interassay CVs were $9.1 \%$ and $15.0 \%$, respectively, and the sensitivity was $5.8 \mathrm{ng}$ inhibin $\mathrm{ml}^{-1}$.

Concentrations of oestradiol were measured in plasma by a double antibody radioimmunoassay kit (Double Antibody Estradiol; Diagnostic Products Corporation, Los Angeles, CA) described for mare samples (Gastal et al., 1999). Intra-assay CV, interassay CV and sensitivity were $14.8 \%, 17.5 \%$ and $0.03 \mathrm{pg}$ oestradiol $\mathrm{ml}^{-1}$, respectively.

\section{Statistical analysis}

Hormone data were tested for normality with a Kolmogorov-Smirnov test (significance level $=0.01$; SAS, 1989); FSH and LH data were log-transformed to correct for lack of normality. In addition, extreme values were tested by Dixon's outlier test $(P<0.05 ;$ Kanji, 1993). As a result, LH concentrations that had consistently markedly increased (>10 ng LH ml${ }^{-1}$ ) from one mare during the late-transitional period ( 0 -follicle group) and one mare during the ovulatory period (all-follicle group) were removed from analyses. Data involving measurements over time (days within periods) were then analysed by the SAS MIXED procedure using a first order autoregressive structure to account for the autocorrelation among samples over time (SAS, 1995). The first ablation of all follicles $>5 \mathrm{~mm}$ in diameter after day 0 in the 0 -follicle groups was carried out using a mean of day 3 . Therefore, a separate analysis was carried out between day 0 and day 3 for the all-follicle and 0 -follicle groups combined. Data between day 0 and day 3 were analysed taking 
Table 1. Follicle characteristics during four periods in the all-follicle group

\begin{tabular}{|c|c|c|c|c|}
\hline \multirow[b]{2}{*}{ Endpoint } & \multicolumn{4}{|c|}{ Period } \\
\hline & $\begin{array}{c}\text { Mid- } \\
\text { anovulatory } \\
(n=4)\end{array}$ & $\begin{array}{c}\text { Early } \\
\text { transitional } \\
(n=8)\end{array}$ & $\begin{array}{c}\text { Late } \\
\text { transitional } \\
(n=5)\end{array}$ & $\begin{array}{c}\text { Ovulatory } \\
\quad(n=5)\end{array}$ \\
\hline Total number of follicles* & $5.0 \pm 0.7^{\mathrm{a}}$ & $13.5 \pm 2.3^{b}$ & $12.2 \pm 3.1^{\mathrm{b}}$ & $6.4 \pm 1.5^{\mathrm{a}, \mathrm{b}}$ \\
\hline Number of days with at least one follicle* & $3.2 \pm 0.2^{\mathrm{a}}$ & $6.7 \pm 0.7^{b}$ & $6.0 \pm 0.7^{b, c}$ & $3.6 \pm 0.7^{\mathrm{a}, \mathrm{c}}$ \\
\hline Number of follicular waves & $2.0 \pm 0.0^{\mathrm{a}}$ & $1.4 \pm 0.2^{b}$ & $1.6 \pm 0.2^{\mathrm{a}, \mathrm{b}}$ & $1.0 \pm 0.0^{b}$ \\
\hline \multicolumn{5}{|l|}{ First post-ablation wave } \\
\hline Wave emergence (day)** & $2.5 \pm 0.9$ & $1.5 \pm 0.3$ & $2.4 \pm 1.0$ & $1.6 \pm 0.2$ \\
\hline Interval (days) from emergence to first $13 \mathrm{~mm}$ follicle & $3.2 \pm 0.2$ & $3.2 \pm 0.3$ & $2.2 \pm 0.4$ & $2.2 \pm 0.2$ \\
\hline Interval (days) for detection of all follicles* & $2.2 \pm 0.2^{\mathrm{a}}$ & $6.5 \pm 1.1^{b}$ & $5.2 \pm 1.7^{a, b}$ & $4.2 \pm 0.8^{a, b}$ \\
\hline Number of follicles* & $3.2 \pm 0.5^{\mathrm{a}}$ & $11.5 \pm 2.6^{b}$ & $8.6 \pm 3.7^{a, b}$ & $6.0 \pm 1.0^{\mathrm{a}, \mathrm{b}}$ \\
\hline Largest follicle (mm) & $17.0 \pm 2.2^{\mathrm{a}}$ & $21.3 \pm 1.5^{\mathrm{a}, \mathrm{b}}$ & $26.6 \pm 1.8^{b}$ & $38.1 \pm 3.1^{\mathrm{c}}$ \\
\hline
\end{tabular}

Values are mean \pm SEM.

* New 13 mm follicles.

**Day 0 is the first day of a period.

a,b,c Means within an endpoint with different superscripts are significantly different $(P<0.05)$.

the animal-within-period as the random effect; main effects of period and day, and the interaction were then determined. Between day 3 and day 13, animal-withinperiod by group was used as the random effect and main effects of period, group and day and the interactions were determined; when interaction(s) was significant, analyses were carried out within each group or within each period using the animal-within-period and the animal-withingroup, respectively, as the random term. The effect of randomizing groups at the beginning of each period on follicle and hormone endpoints was evaluated by analysing for the different endpoints within each period that included group assignment during previous periods as a main effect. Single-point measurements within periods were analysed by the SAS MIXED procedure using the animal as the random term and determining the main effect of period. Tukey's multiple range tests were used to detect differences between or among means. Significance was defined by $P<0.05$, whereas probabilities from $P=0.05$ to $<0.1$ were considered as approaching significance.

\section{Results}

Data from three mares ovulating within 30 days after the beginning of the experiment were removed, as planned. Data from the early-transitional period were not used in two mares because an ovary became enlarged after day 0 in each mare. Data from another mare were not included during the ovulatory period because a haemorrhagic follicle (Ginther, 1992) was detected on day 0. Two other mares were not available during the ovulatory period. In total, four and six mares were available for analysis in the all-follicle and 0 -follicle groups, respectively, during the mid-anovulatory period; eight and three mares during the early-transitional period; five and eight mares during the late-transitional period; and five and five mares during the ovulatory period. The diameter of the largest follicle and circulating concentrations of oestradiol, total inhibin, $\mathrm{FSH}$ and $\mathrm{LH}$ were not affected $(P>0.1)$ during any period by the group assignment during previous periods. Mares ovulated 63-134 days after the beginning of the experiment on 29 January (mean, $97.5 \pm 7.2$ days). The mean date of the first ovulation was 5 May. For each of the mid-anovulatory, early-transitional and late-transitional periods, the interval from the beginning of the period to the first ovulation was not significantly different between the all-follicle and 0-follicle groups. Combined for the two groups, the three periods began at means of $98.5 \pm 4.2,61.4 \pm 1.6$ and $26.0 \pm 1.4$ days before the first ovulation, respectively. The interval from the beginning of the ovulatory period to the second ovulation was $12.8 \pm 0.7$ and $21.7 \pm 0.9$ days $(P<0.0001)$ for the all-follicle and 0-follicle groups, respectively. Singlepoint follicle endpoints for the all-follicle groups are shown for the 13 day periods (Table 1 ).

The mean diameter of the largest follicle and circulating hormone concentrations during each of the four periods from day 0 to day 3 averaged over the allfollicle and 0 -follicle groups and from day 3 to day 13 for each of the two groups are shown (Fig. 2). The diameter of the largest follicle increased between day 1 and day 3 combined for the four periods, as indicated by a day effect. Three-factor analysis (day, period and group) during days 3-13 did not indicate a three-way interaction for any endpoint $(P>0.1)$. The group-by-day interaction for diameter of the largest follicle between day 3 and day 13 resulted primarily from a progressive 


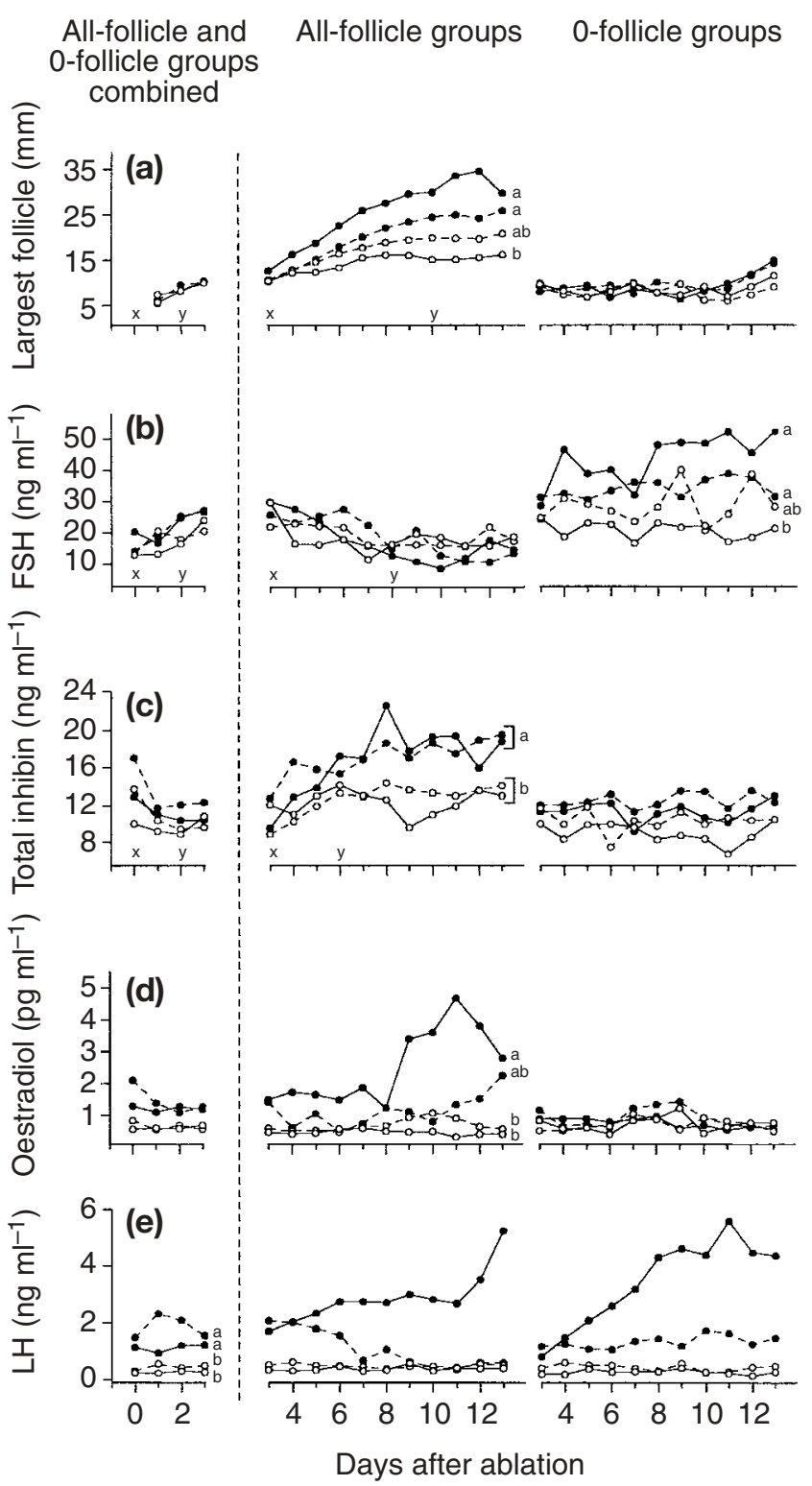

Fig. 2. Mean diameter of (a) the largest follicle and circulating concentrations in mares of (b) FSH, (c) total inhibin, (d) oestradiol, and (e) LH during the mid-anovulatory period (-O-), early transitional period (-- - - - - ), late transitional period (---- - - -) and ovulatory period (--), from day 0 to day 3 combined for the allfollicle and 0 -follicle groups, and from day 3 to day 13 for each of the two groups. Between day 0 and day 3 , there was an effect of day $(P<0.0001)$ for diameter of the largest follicle, total inhibin and $\mathrm{FSH}$, and an effect of period $(P<0.0001)$ for $\mathrm{LH}$. Between day 3 and day 13 , there were interactions of group $\times$ day $(P<0.0001)$ and group $\times$ period $(=0.0009)$ for diameter of the largest follicle, group $\times$ day $(P=0.001)$ and group $\times$ period $(P=0.03)$ for $\mathrm{FSH}_{\text {, }}$ group $\times$ day $(P<0.0001)$ for total inhibin, group $\times$ period $(P=$ $0.04)$ for oestradiol, and period $\times$ day $(P<0.0001)$ for LH. Overall, SEMs for diameter of the largest follicle and concentrations of total inhibin, oestradiol and LH were $0.5,0.9,0.3,0.1$, and 0.1 , respectively, between day 0 and day 3 , and $0.3,0.7,0.2,0.06$, and 0.07 , respectively, between day 3 and day 13 . Means for days with different letters $(x, y)$ are significantly different $(P<0.05)$ for the increase $(P<0.0005)$ in mean diameter after day 3 in the all-follicle groups for all periods combined, but not in the 0 -follicle groups. The diameter of the largest follicle in the 0 -follicle groups increased $(P<0.05)$ between day 11 and day 13 for all periods combined. The group-byperiod interaction for diameter of the largest follicle was associated with a progressively larger $(P<0.05)$ mean diameter for the largest follicle over the mid-anovulatory and ovulatory periods in the all-follicle groups.

A day effect for circulating FSH concentrations during days $0-3$ indicated an increase after ablation for all periods combined. A group-by-day interaction during days $3-13$ resulted primarily from a decrease $(P=0.02)$ for all periods combined from day 3 to day 8 in the allfollicle groups but not in the 0 -follicle groups $(P>0.1)$. FSH concentrations were lower $(P<0.05)$ during days $6-13$ in the all-follicle groups combined than in the 0follicle groups combined. The diameter of the largest follicle at the beginning of the decline in $\mathrm{FSH}$ was similar $(P>0.1)$ in the all-follicle groups during the four periods (overall mean, $13.0 \pm 0.8 \mathrm{~mm}$ ). An interaction of group by period for $\mathrm{FSH}$ concentrations was associated with an effect of period $(P=0.01)$ in the 0 -follicle but not the all-follicle groups $(P>0.1)$. In the 0 -follicle groups, FSH concentrations were higher $(P<0.04)$ during the late-transitional and ovulatory periods than during the mid-anovulatory period.

A day effect for total inhibin concentrations between day 0 and day 3 reflected a decrease after ablation for the four periods combined. Between day 3 and day 13, an interaction of group by day resulted mostly from an increase $(P=0.006)$ in concentrations, averaged over all periods, between day 3 and day 6 in the all-follicle but not the 0 -follicle-groups. For all periods combined, total inhibin concentrations were higher $(P<0.05)$ in the allfollicle than in the 0 -follicle groups during each of days 6-13. Although there was no main effect or interactions involving period $(P>0.1)$, total inhibin concentrations within the all-follicle groups were higher $(P=0.01)$ for the late-transitional and ovulatory periods combined than for the two earlier periods combined.

There were no significant main effects or interaction of day and period for circulating oestradiol concentrations during days $0-3$. The group-by-period interaction during days 3-13 resulted mainly from an effect of period $(P=0.01)$ in the all-follicle but not the 0 -follicle groups $(P>0.1)$. Within the all-follicle groups, oestradiol concentrations were higher $(P<0.05)$ during the ovulatory period than during each of the mid-anovulatory and early-transitional periods, and an interaction of period by day approached significance $(P=0.06)$. The interaction reflected primarily an increase $(P<0.05)$ in

four periods combined. Means for periods, individual or combined, with different letters $(a, b)$ are different $(P<0.05)$ for all days combined. 
concentrations from day 8 to day 11 during the ovulatory period.

Between day 0 and day 3, circulating $\mathrm{LH}$ concentrations were higher $(P<0.05)$ during each of the latetransitional and ovulatory periods than during each of the two earlier periods, as indicated by a period effect. A period-by-day interaction during days 3-13 resulted mainly from an increase $(P<0.001)$ in concentrations for the all-follicle and 0-follicle groups combined during the ovulatory period but not during the other periods. Averaged over the two groups, concentrations were higher $(P<0.05)$ on each day during the ovulatory period than during each of the mid-anovulatory and early-transitional periods and during the late-transitional period than during the mid-anovulatory period. In addition, the concentrations were higher $(P<0.05)$ during the late-transitional period than during the earlytransitional period on days 3, 4, 8, 10 and 11, and during the ovulatory period than during the late-transitional period on each day from day 7 to day 13 .

\section{Discussion}

The standardization of follicle status by ablation of all follicles is a novel approach for studying follicle growth and associated changes in circulating hormones during the anovulatory season. Day-to-day identification of individual small follicles after ablation permitted the characterization of individual follicular waves beginning when the largest follicle was $6 \mathrm{~mm}$ in diameter. In follicle-intact (no follicles ablated) mares, follicular waves were statistically identified during the last half of the anovulatory season (Donadeu and Ginther, 2002a). However, some waves appeared to be masked by regressing follicles from previous waves, and a follicular wave in association with the ovulatory follicle at the end of the season was identified in only one of eight mares. The present follicle-ablation approach demonstrated that a consistent wave-generating capability is present throughout the second half of the anovulatory season and early-ovulatory season. In the all-follicle groups, a distinct follicular wave that began at the end of the late-transitional period gave origin to the first ovulatory follicle in all mares, demonstrating for the first time the association between the first ovulatory follicle and the wave phenomenon. The contrasts between the previous and present results are attributable to the ablation procedure, which removed the extensive follicle background, thereby facilitating the identification of emerging waves.

The designation of the three periods before ovulation was based on similarities with the study of Donadeu and Ginther (2002a) of diameter of the largest follicle, number of identified follicles, and number of days to the first ovulation. Follicular activity in the present study was greater for the two transitional periods than for the mid- anovulatory period as indicated in the all-follicle groups by (1) more new $13 \mathrm{~mm}$ follicles and more days with at least one new $13 \mathrm{~mm}$ follicle during each transitional period; (2) longer interval for detection of all new $13 \mathrm{~mm}$ follicles and more $13 \mathrm{~mm}$ follicles in the first postablation wave during the early-transitional period than during the mid-anovulatory period; and (3) greater mean diameter of the largest follicle during the late-transitional period than during the mid-anovulatory period. These results are consistent with the greater follicular activity during the transitional period reported for follicle-intact mares (Donadeu and Ginther, 2002a). In contrast to the other periods, only one wave developed during the ovulatory period in each mare of the all-follicle group. In addition, the number of days during which at least one new $13 \mathrm{~mm}$ follicle was detected in the all-follicle groups was lower during the ovulatory period than during the early-transitional period. These results are attributable to the suppression of the growth of new follicles by the dominant follicle of the post-ablation wave (reviewed in Ginther, 2000).

A post-ablation increase in circulating FSH was associated consistently with the emergence of a follicular wave, in agreement with results in follicle-intact mares (Donadeu and Ginther, 2002a) and ewes (Bartlewski et al., 1999; Evans et al., 2001) during the anovulatory season. However, in the follicle-intact mares (Donadeu and Ginther, 2002a), an associated wave was not detected for all FSH surges, which was at least partly attributable to the masking effect of one wave encroaching on another. In the present study, the postablation surge in FSH was similar during the four periods despite the much lower follicle activity for the waves of the mid-anovulatory period and the gradual increase in the diameter of the largest follicle of the waves as the anovulatory season progressed. These results support the previous conclusion (Donadeu and Ginther, 2002a) that factors other than the nature of the FSH surge account for the greater follicle response during the transitional period than during the middle of the anovulatory season.

There was a temporal association between an increase in FSH and a decrease in total inhibin between day 0 and day 3 averaged over all periods and between a decrease in $\mathrm{FSH}$ and increase in total inhibin during the post-ablation wave in the all-follicle group of each period. Similar relationships between FSH and total inhibin during follicular waves were previously reported during the anovulatory season but without consideration of the hormone changes associated with early wave development (Donadeu and Ginther, 2002a). In the present study, the decline in circulating FSH began when the largest follicle reached a similar mean diameter for the four periods (overall mean, $13.0 \mathrm{~mm}$ ). This diameter is close to the diameter of $13.7 \mathrm{~mm}$ reported for the largest follicle at the beginning of the decline in $\mathrm{FSH}$ after the ablation of all follicles $>5 \mathrm{~mm}$ in diameter during the middle of an oestrous cycle (Donadeu and Ginther, 
2001). Apparently, the follicles of a wave acquire the capacity to suppress FSH at a similar stage of development in seasonally anovulatory and ovulatory mares.

Total inhibin concentrations during a follicular wave were similar for the mid-anovulatory and earlytransitional periods, as reported by Donadeu and Ginther (2002a), despite an increase between the two periods in the number of follicles in the post-ablation wave from approximately three to 12 . This is consistent with the finding during the ovulatory season that the three largest follicles of a wave are as effective as all follicles in increasing circulating total inhibin (Donadeu and Ginther, 2001). Inhibin concentrations were higher for the late-transitional and ovulatory periods, in agreement with results in follicle-intact mares (Donadeu and Ginther, 2002a; Watson et al., 2002). The mean diameter of the largest follicle increased from 21 to $27 \mathrm{~mm}$ between the early-transitional and late-transitional periods, indicating that follicles $>21 \mathrm{~mm}$ had a higher capacity to produce inhibin than smaller follicles. This conclusion is supported by previous results during both the anovulatory season (Donadeu and Ginther, 2002a) and the ovulatory season (Bergfelt et al., 2001; Donadeu and Ginther, 2001, 2002b).

There was support for the first hypothesis that the wave-associated FSH decline is similar between the mid-anovulatory and transitional periods, despite higher circulating inhibin concentrations associated with transitional waves. This was indicated in the all-follicle groups by no differences in circulating $\mathrm{FSH}$ among the four periods, despite higher circulating total inhibin during the late-transitional and ovulatory periods. There was also support for the second hypothesis that the absence of an increased response of circulating $\mathrm{FSH}$ to the increased circulating inhibin during transition is accounted for by positive effects of season on FSH. This was indicated by higher FSH concentrations in the 0 -follicle groups during the late-transitional and ovulatory periods than during the mid-anovulatory period. A seasonal increase in circulating FSH has been reported in ovariectomized mares during the months corresponding to the transition into the ovulatory season (Freedman et al., 1979). This increase in FSH appears to be mediated by an increase in the hypothalamic content of GnRH (Hart et al., 1984) and in secretion of GnRH (Sharp and Grubaugh, 1987). The present results indicate that the additional inhibin suppression associated with a follicular wave during the late-transitional and ovulatory periods counteracted the season-mediated stimulatory effect on $\mathrm{FSH}$, resulting in a decline in circulating $\mathrm{FSH}$ to concentrations similar to those observed during the mid-anovulatory and early-transitional periods.

Circulating oestradiol concentrations did not change significantly in association with follicular waves during the mid-anovulatory, early-transitional and latetransitional periods, in agreement with the results for follicle-intact mares (Donadeu and Ginther, 2002a). An increase (non-significant) in concentrations beginning at a mean of 14 days before the first ovulation of the year (end of late-transitional period) in the all-follicle groups is in agreement with previous reports (Peltier et al., 1998; Donadeu and Ginther, 2002a). During the ovulatory period, circulating oestradiol increased between day 8 and day 11 in association with the development of the dominant follicle, as reported by Gastal et al. (1999) and Bergfelt et al. (2001).

Circulating LH concentrations were lowest during the mid-anovulatory and early-transitional periods, in agreement with previous studies (Silvia et al., 1986, 1987, 1992; Donadeu and Ginther, 2002a). The increased circulating LH during the late-transitional and ovulatory periods was likely attributable to increases in mRNA expression (Sharp et al., 2001), pituitary content (Hart et al., 1984; Silvia et al., 1986) and secretion (Silvia et al., 1987). Comparison of circulating LH between the all-follicle and 0 -follicle groups indicated that the higher circulating LH during the late-transitional and ovulatory periods was independent of the follicles. In agreement with this finding, an increase in circulating $\mathrm{LH}$ at the end of the anovulatory season occurs in both ovary-intact and ovariectomized mares (Freedman et al., 1979; Affleck et al., 1991; Peltier et al., 1998). The temporal association during the ovulatory period between a preovulatory $\mathrm{LH}$ surge in the all-follicle group and a similar increase in $\mathrm{LH}$ in the 0 -follicle group was consistent with results during the middle of the ovulatory season (Donadeu, 2002) and indicated that the LH stimulation did not depend on an increase in circulating oestradiol. The present results are in contrast with the results of Sharp et al. $(1991,2001)$, indicating that positive oestradiol feedback is involved in preovulatory LH surges in mares. The role of oestradiol versus season in the stimulation of LH during the ovulatory season should be clarified.

The third hypothesis of an association between an increase in follicle activity and an increase in circulating $\mathrm{LH}$ at the beginning of transition was intended to explain the increased follicle activity despite the consistency in FSH surges. The hypothesis was not supported, as indicated by the lack of significant changes in $\mathrm{LH}$ concentrations in association with the increase in follicular activity during the early-transitional period. A progressive increase in circulating $\mathrm{LH}$ pulse frequency has been reported throughout the second half of the anovulatory season (Fitzgerald et al., 1987), but the changes in LH pulsatility were not studied in relation to follicle events.

In summary, follicular waves developed after follicle ablation in all mares in the all-follicle groups during all anovulatory periods as well as the ovulatory period. Follicular activity increased from the mid-anovulatory period to the transitional periods as indicated by an increase in the diameter of the largest follicle and number of follicles; nevertheless, the wave-associated FSH surges were similar. During all periods, the growing follicles of 
the post-ablation wave produced inhibin, and temporal relationships indicated that the follicular inhibin was involved in the suppression of circulating $\mathrm{FSH}$. The development of large follicles (>21 $\mathrm{mm}$ in diameter) during the late-transitional and ovulatory periods relative to earlier periods resulted in higher circulating inhibin concentrations than during earlier periods. This increased inhibin apparently counteracted a positive seasonal effect on $\mathrm{FSH}$, as demonstrated in the 0 -follicle groups of the late-transitional and ovulatory periods. As a result, the wave-associated decrease in $\mathrm{FSH}$ was similar during all periods. Circulating LH increased between the earlytransitional and late-transitional periods and throughout the 13 days of the ovulatory period in both the allfollicle and 0 -follicle groups. These increases were not attributable to the follicles but to the positive effects of season.

The authors thank J. A. O'Sullivan for technical assistance and A. F. Parlow from the National Hormone and Pituitary Program for gonadotrophin radioimmunoassay reagents.

\section{References}

Affleck KJ, Conboy HS and Fitzgerald BP (1991) A negative feedback role for the ovaries of the mare on tonic LH secretion before the first ovulation of the breeding season Journal of Reproduction and Fertility Supplement 44 241-247

Alexander SL and Irvine CHG (1991) Control of onset of the breeding season in the mare and its artificial regulation by progesterone treatment Journal of Reproduction and Fertility Supplement 44 307-318

Bartlewski PM, Beard AP and Rawlings NC (1999) Ovarian function in ewes during the transition from breeding season to anoestrus Animal Reproduction Science 57 51-66

Bergfelt DR, Gastal EL and Ginther OJ (2001) Response of estradiol and inhibin to experimentally reduced luteinizing hormone during follicle deviation in mares Biology of Reproduction 65 426-432

Davis SD and Sharp DC (1991) Intra-follicular and peripheral steroid characteristics during vernal transition in the pony mare Journal of Reproduction and Fertility Supplement 44 333-340

Donadeu FX (2002) Follicular Growth and Regulation of Circulating Concentrations of FSH and LH During the Ovulatory and Anovulatory Seasons in Mares PhD Thesis, University of Wisconsin, Madison, WI

Donadeu FX and Ginther OJ (2001) Effect of number and diameter of follicles on plasma concentrations of inhibin and $\mathrm{FSH}$ in mares Reproduction 121 897-903

Donadeu FX and Ginther OJ (2002a) Follicular waves and circulating concentrations of gonadotrophins, inhibin and oestradiol during the anovulatory season in mares Reproduction 124 875-885

Donadeu FX and Ginther OJ (2002b) Changes in concentrations of follicular fluid factors during follicle selection in mares Biology of Reproduction 66 1111-1118

Evans ACO, Duffy P, Quinn KM, Knight PG and Boland MP (2001) Follicular waves are associated with transient fluctuations in $\mathrm{FSH}$ but not oestradiol or inhibin-A concentrations in anoestrous ewes Animal Science 72 $547-554$

Fitzgerald BP, Affleck KJ, Barrows SP, Murdoch WL, Barker KB and Loy RG (1987) Changes in LH pulse frequency and amplitude in intact mares during the transition into the breeding season Journal of Reproduction and Fertility 79 485-493

Freedman LJ, Garcia MC and Ginther OJ (1979) Influence of photoperiod and ovaries on seasonal reproductive activity in mares Biology of Reproduction 20 567-574
Gastal EL, Gastal MO, Bergfelt DR and Ginther OJ (1997) Role of diameter differences among follicles in selection of a future dominant follicle in mares Biology of Reproduction 57 1320-1327

Gastal EL, Gastal MO, Wiltbank MC and Ginther OJ (1999) Follicle deviation and intrafollicular and systemic estradiol concentrations in mares Biology of Reproduction 61 31-39

Ginther OJ (1992) Reproductive Biology of the Mare: Basic and Applied Aspects pp 141-144, 151. Equiservices Publishing, Cross Plains, WI, USA

Ginther OJ (1995) Ultrasonic Imaging and Animal Reproduction: Book 1, Fundamentals pp 94-95. Equiservices Publishing, Cross Plains, WI, USA

Ginther OJ (2000) Selection of the dominant follicle in cattle and horses Animal Reproduction Science 60-61 61-79

Ginther OJ and Kot K (1994) Follicular dynamics during the ovulatory season in goats Theriogenology 42 987-1001

Hart PJ, Squires EL, Imel KJ and Nett TM (1984) Seasonal variation in hypothalamic content of gonadotropin-releasing hormone $(\mathrm{GnRH})$, pituitary receptors for $\mathrm{GnRH}$, and pituitary content of luteinizing hormone and follicle-stimulating hormone in the mare Biology of Reproduction 30 1055-1062

Kanji GK (1993) 100 Statistical Tests Sage Publications, London

Peltier MR, Robinson G and Sharp DC (1998) Effects of melatonin implants in pony mares. 2. Long-term effects Theriogenology 49 1125-1142

Roser JF, McCue PM and Hoye E (1994) Inhibin activity in the mare and stallion Domestic Animal Endocrinology 11 87-100

SAS Institute Inc. (1989) SAS/STAT ${ }^{T M}$ User's guide Version 6, Edn 4. SAS Institute Inc., Cary, NC, USA

SAS Institute Inc. (1995) Introduction to the MIXED Procedure SAS Institute Inc., Cary, NC, USA

Sharp DC and Grubaugh WR (1987) Use of push-pull perfusion techniques in studies of gonadotropin-releasing hormone secretion in mares Journal of Reproduction and Fertility Supplement 35 289-296

Sharp DC, Grubaugh WR, Weithenauer J, Davis SD and Wilcox CJ (1991) Effects of steroid administration on pituitary luteinizing hormone and follicle-stimulating hormone in ovariectomized pony mares in the early spring; pituitary responsiveness to gonadotropin-releasing hormone and pituitary gonadotropin content Biology of Reproduction 44982 990

Sharp DC, Wolfe MW, Cleaver BD and Nilson J (2001) Effects of estradiol$17 \beta$ administration on steady-state messenger ribonucleic acid (mRNA) encoding equine $\alpha$ and $\mathrm{LH} / \mathrm{CG} \beta$ subunits in pituitaries of ovariectomized pony mares Theriogenology 55 1083-1093

Silvia PJ, Squires EL and Nett TM (1986) Changes in the hypothalamichypophyseal axis of mares associated with seasonal reproductive recrudescence Biology of Reproduction 35 897-905

Silvia PJ, Squires EL and Nett TM (1987) Pituitary responsiveness of mares challenged with $\mathrm{GnRH}$ at various stages of the transition into the breeding season Journal of Animal Science 64 790-796

Silvia PJ, Johnson L and Fitzgerald BP (1992) Changes in the hypothalamichypophyseal axis of mares in relation to the winter solstice Journal of Reproduction and Fertility 96 195-202

Turner DD, Garcia MC and Ginther OJ (1979) Follicular and gonadotropic changes throughout the year in pony mares American Journal of Veterinary Research 40 1694-1700

Watson ED and Al-zi'abi MO (2002) Characterization of morphology and angiogenesis in follicles of mares during spring transition and the breeding season Reproduction 124 227-234

Watson ED, Heald M, Tsigos A, Leask R, Steele M, Groome NP and Riley SC (2002) Plasma FSH, inhibin A and inhibin isoforms containing pro- and $-\alpha \mathrm{C}$ during winter anoestrus, spring transition and the breeding season in mares Reproduction 123 535-542

Received 12 November 2002.

First decision 3 January 2003.

Revised manuscript received 16 January 2003.

Accepted 16 January 2003. 